\title{
Comparison parasitological diagnostic techniques of gastro-intestinal parasitic infections of horses in Maiduguri, North Eastern Nigeria
}

\author{
Abdullahi Abubakar Biu" ${ }^{1}$, Gwana Adamu Mohaammed" ${ }^{2,}$, Bukar-Kolo M. Yachilla ${ }^{3}$, \\ Bassey Effiong Edet ${ }^{4}$, Uvu Usman Sha'aibu ${ }^{2}$, Aja Makinta ${ }^{2}$, Abdullahi Mumin Mai ${ }^{2}$, \\ Modu Gana Umara ${ }^{1}$ \\ ${ }^{1}$ Department of Veterinary Microbiology, Parasitology and Virology, Faculty of Veterinary Medicine, University of Maiduguri, Nigeria \\ ${ }^{2}$ Laboratory Unit, A.H.P Department, Mohamet Lawan College of Agriculture, P.M.B. 1427, Maiduguri, Nigeria \\ ${ }^{3}$ Dept.of Medicine, Faculty of Veterinary Medicine, Unimaid, Maiduguri, Nigeria \\ ${ }^{4}$ Department of Microbiology, Nnamdi Azikwe University, Awka, Nigeria
}

\section{Email address:}

biuvet@yahoo.com (A. A. Biu), admuwana@yahoo.com (Gwana A. M.), yachillabukar@yahoo.com (Bukar-Kolo M. Y.), edetbassey69@gm.com (Bassey E. E.), mumin_abdullahi@yahoo.com (Abdullahi M. M.)

\section{To cite this article:}

Abdullahi Abubakar Biu, Gwana Adamu Mohaammed, Bukar-Kolo M. Yachilla, Bassey Effiong Edet, Uvu Usman Sha'aibu, Aja Makinta, Abdullahi Mumin Mai, Modu Gana Umara. Comparison Parasitological Diagnostic Techniques of Gastro-Intestinal Parasitic Infections of Horses in Maiduguri, North Eastern Nigeria. American Journal of Biomedical and Life Sciences. Vol. 2, No. 6, 2014, pp. $150-155$.

doi: $10.11648 /$ j.ajbls.20140206.13

\begin{abstract}
This research study was conducted to determine the incidence of Gastrointestinal Parasites Infection of Horses in Maiduguri, Nigeria. Thirty (30) Horses were selected randomly from Shukari - Maidokiri, Maiduguri. Comparative parasitological diagnostic techniques were applied (both macroscopic and microscopic examinations of direct smears and concentration techniques) and the results obtained revealed mean total infectivity of $20 \%$. The macroscopic examination of the faecal samples revealed mean prevalence of $21 \%$, while the microscopic examination of the faecal samples using $0.85 \%$ Normal saline solution direct smear wet preparation technique; protozoan cysts and their vegetative form, helminths ovae and larvae form found are 28\%, Lugol's iodine solution direct smear are 34\%, concentration technique by floatation using saturated salt solution of sodium chloride are 35\% mean of infectivity. From these 3 techniques were applied; the mean total infectivity of protozoan cysts are $36 \%$, vegetative forms $17 \%$, helminths ova $29 \%$, larvae $17 \%$ and adult Parasite found $0 \%$. When multiples diagnostic techniques are been applied, the possibility of missing any Parasite will be exceptional, it will reveals a higher results of positivity if infected. Owners of Horses were urged to take their horses to a Veterinary clinic or hospital nearby for an accurate and appropriate diagnosis, for the wellbeing of their animal routinely.
\end{abstract}

Keywords: Diagnostic Techniques, Examination, Gastrointestinal, Horse, Infectivity, Macroscopic, Microscopic, Parasites

\section{Introduction}

Horse is a large land mammal notable for its speed, strength, and endurance. Horse is known as "Doki" and the plural is known as "Dawakai" in Hausa language, while in Kanuri language is known as "Fur". Horses are members of the Equidae family, which also includes Zebras and Asses. Like all equids, the horse is extremely well adapted to travelling long distances with great efficiency and to surviving on a diet of nutrient-poor, high-fibre grasses. Horses belong to the family Equidae of the order
Perissodactyla. The domestic horse is classified as Equus caballus, and Przewalski's horse is classified as Equus caballus przewalskii, [2, 15]. Horse is an intensely social animal, forming strong associations with members of its herd and possessing a keen ability to recognize subtle social cues. These instinctive behaviours form the basis of the horse's ability to bond with and obey a human trainer, [2, 7]. Horse's influence on human history and civilization make it one of the most important domestic animals. Horses were 
domesticated in Eurasia around 6,000 years ago, they have provided humans with mobility and have served in agriculture, warfare, and sport. Today domestic horses are found throughout the world, with a total population estimated at 60 million. So-called wild horses, such as those found in the American west, are actually feral animals, free-living descendants of domestic horses that escaped or were turned loose $[2,14]$. Horses were also used for drawing water from deep wells and as hay wagons, harrowing and every kind of agricultural implement. They were also used for sports such as Polo, hunting, racing, traction, teaching demonstration and scientific research, recreation purposes and as well as slaughtered for meat production and consume in some countries. The mounted troop police used them to help in crime control, land patrol and were taught to face loud noises, bang and flang weaving $[1,2]$. Horses at times, suffer from various diseases such as parasitic infection. The endoparasites (internal parasites e.g. cestodes, nematodes, trematodes) which are more common in all domesticated animals, caused a damage which many of them are blood suckers and as a result may cause anaemia or others may cause occlude or twist the intestine resulting to digestive disturbances and death. Net results or parasitism with endo parasite is less in production [2, 5, 15]. Gastro-intestinal worms of Equine, commonly called the intestinal worms of horses, are parasitic worm that infects and found in the stomach of horses. These are various types, the protozoan and the helminthic parasites, $[5,7,10]$. Protozoa are single celled, microscopic parasites several types can infect the horses digestive tract and caused a serious, severe stomach disorder, e.g. Cryptosporidiosis, and the source of infection is the cysts (Oocysts) containing the parasite [7,10].. These are excreted in the faeces of infected horses or other infected animals such as rodents or farm cats. The disease condition is of more severe diarrhoea with at times viral infection which is very common. Faeces are yellow or pale and contain mucus. This may results in weight loss and emaciation with apathy, poor appetite and mild condition. Dehydration, weakness and collapse are rare especially in foals. The diagnoses of the disease infection are based on the laboratory detection of oocyst or vegetative form in fresh faecal sample of the infected Horses, $[1,7,10,12,13]$. Giardiasis is also a Protozoan infection which is a chronic, intestinal protozoan infection that is seen worldwide in most domestic and wild mammals, many birds and people. Infection is common in dogs and cats, it is rare in horses. Infected animals passed faeces with mucus and bloody yellowish diarrhoeal faeces. Diagnosis is by the detection of cysts or vegetative form of the parasites in fresh faeces passed by the infected horse [1, $14,15,16]$. [15] enumerated the common gastro intestinal helminthic parasites of horses, their predilection site, treatment and prevention management in Equine worms of the digestive track, which include; Habronema species, Gastrophilus species (Bots), Strongylus species, Parascuris equorum, e.t.c. Most of these parasites infect both stages of horses, mostly infect the gastrointestinal tract were they cause stomach disorder and other diseases conditions. The diagnoses are through the detection of the ova, larva, adult parasites or both in fresh sample of an infected horse $[6,8,9$, $15,17]$. The objective of this study is to determine the percentage incidence of Gastro intestinal parasitic infection amongst horses, through various parasitological diagnostic techniques, in Maiduguri, North - Eastern Nigeria.

\section{Methodology}

\subsection{Area and Location}

The study was conducted in Shukari - Maidokiri, Maiduguri, Nigeria. It has an area land-mark of 300 square kilometres $\left(300 \mathrm{~km}^{2}\right)$, which lies between latitude $12^{0}$ North to $13^{0}$ North and longitude $13^{0}$ East to $15^{0}$ East respectively. The climatic condition in this area is of a hot dry season $\left(27^{\circ} \mathrm{C}\right.$ to $42^{\circ} \mathrm{C}$ ), and an annual rainfall of 500 to $600 \mathrm{~mm}$ has been recorded [4]. It has an estimated population of 629,486 people, out of which 340,809 are males and 288,977 are females [11].

\subsection{Materials}

\subsubsection{Reagents}

$70 \%$ alcohol (Methylated spirit), 1\% Lurgols' iodine solution, $0.85 \%$ physiological saline solution, $10 \%$ formal saline solution, saturated salt solution of sodium chloride Analar (SSS $\mathrm{NaCl}$ Analar), distilled water, hypochlorite solution (bleach solution as viral disinfectant), medicated soap "Dettol," petroleum jelly and dusting powder (as hand desiccator).

\subsubsection{Apparatus}

Electrical binocular microscope, sieve (wire gauze), funnel, test - tubes ( $8 \mathrm{~cm}$ by $2 \mathrm{~cm}$ size), Pasteur pipettes, test - tube rack or stand, glass slides, cover slips, applicator sticks, large mouth polythene bottles or containers with screw caps (for faecal specimen collection), absorbable cotton wool, surgical hand gloves, hand towel and waste bin.

\subsection{Methods}

The methods were used in this research study were the Parasitological techniques as in Stoll's method described by 13] and that of [17]. All the bio-security measures were seriously been observed and taken in order to avoid contamination and disease infection. The methods were designed in to five (5) experimental stages. These stages are;

\subsubsection{Faecal Sample Collection \\ Procedure:}

Faecal samples of horses were collected from the randomly selected households within the Maiduguri Metropolis. Hands were washed with a lot of water and disinfectant soap, thoroughly, cleaned and dried with a hand towel. Dusting powder was applied on to both hands and later surgical glove were worn. The horses were restrained by the owners; one hand was inserted into a white polythene bag and then scrubbed the faeces within the anus of the horses. 
The faecal samples scrubbed out of the anus of horses were then transferred each in to large mouth Plastic bottle and screwed caped, labelled with the following information; time and date of collection, breed types, physical condition of the horse and its skin, and the house hold numbers were given to each house were sample being collected. The sample were packed in cold-chain container and transported to the Laboratory for the examinations.

\subsubsection{Macroscopic Examination of Faecal Sample of Horses}

This technique allowed the differentiation in the diagnosis of parasitic, bacterial infection or both by observing normal or abnormal, and formed or unformed stool.

Procedure:

The benches of the laboratory was cleaned and disinfected by using hypochlorite solution, soaked in an absorbable cotton wool, prior to and after the examination procedure taken. The faecal sample were removed from the cold-chain box and allowed to stand on the bench until they acquired room temperature. The samples were examined macroscopically for the presence of any larva or adult parasite or both. The odour of the faecal samples was perceived for offensiveness or non offensiveness, the abnormality or normality of the colour and consistency were observed. Presence or absences of blood, mucus, and undigested food particles were noted and the results taken were recorded.

\subsubsection{Microscopic Examination of Faecal Sample of Horses}

This technique allowed the magnification of the object (parasite) a larger and easily to be seen under the microscope.

\subsubsection{Wet Preparations by using Normal Saline Direct Smear}

This technique allowed the differentiation in the diagnosis of various different live protozoan parasites.

Procedure:

On the centre of a clean grease free glass slide, two drops of normal saline solution were dropped. A portion of the surface parts of the faecal sample was taken with a wooden applicator stick and thoroughly emulsified in the drops of normal saline solution. Larger faecal particles were carefully removed, in such a way to avoid the preventing of the clean grease free cover slip lying properly on the wet film. The suspension preparation was in such a way that, to be sufficiently thin to allowed the transmission of light through it easily, so that, a hand of a wrist watch could be seen. Much fluid was avoided in such a way not to allow the cover slip to float or move about when placed on the suspension preparation. A number 1, cleaned grease free cover slip was used to cover the suspension, mounted onto the stage of the electrical binocular microscope and examined thoroughly with $\mathrm{x} 10$ and $\mathrm{x} 40$ objective lenses for the presence of parasites cysts, larvae and ova, and recorded.

\subsubsection{Wet Preparation by using 1\% Lurgols' Iodine Direct Smear}

This technique allowed the differentiation in the diagnosis of various different parasites cysts, larvae and ova.

Procedure:

On to the centre of a clean grease free glass slide, two drops of the $1 \%$ Lurgols' iodine solution were dropped. A portion of the faecal sample from the surface parts was taken with a wooden applicator stick and thoroughly emulsified in the drops of normal saline solution in the centre of the glass slide. Larger faecal particles were carefully removed, in such a way to avoid the preventing of the clean grease free cover slip lying properly on the wet film. The suspension preparation was in such a way that, to be sufficiently thin to allowed the transmission of light through it easily, so that, a hand of a wrist watch could be seen through. Also, so much fluid was avoided in such a way not to allow the cover slip to float or move about when placed on the suspension preparation. A number 1, cleaned grease free cover slip was used to cover the suspension, mounted onto the stage of the electrical binocular microscope and examined thoroughly with $\mathrm{x} 10$ and $\mathrm{x} 40$ objective lenses for the presence of parasites cysts, larvae and ova, and the findings were recorded.

\subsubsection{Concentration Technique by using Saturated Salt Solution of $\mathrm{NaCl}$}

This technique allowed the differentiation in the diagnosis of various different parasites cysts, larvae and ova which are been concentrated, especially if they are scanty, that is, if they are very few in the faeces as in the case of early infection or parasites load, in which large amount or weight of faecal sample are used.

Procedure:

With the aid of an applicator stick, a portion of the faecal sample from the outer surface part weighed 2 gram $(2 \mathrm{~g})$ was taken, placed into a test-tube of a length and diameter size of $8 \mathrm{~cm}$ by $2 \mathrm{~cm}$, and distilled water was added to a one quarter (1/4) full. It was then corked tightly and vigorously shaken until the faecal sample was completely emulsified. It was then filtered into another test-tube of the same sizes by using funnel and sieve of $2 \mathrm{~mm}$ wire gauze in order to remove larger faecal particles. Saturated salt solution of sodium chloride (SSS of $\mathrm{NaCl}$ ) was then added to, until the tube was three quarters $(3 / 4)$ full, vigorously shaken and mounted on to the test-tube rack placed on the bench to stand. By using pipette, more solution of the SSS of $\mathrm{NaCl}$ was added carefully up to the rim of the test-tube. That is, meniscus of the fluid was levelled with the mouth of the test-tube. It was then covered with a cleaned grease free cover slip gently. Overflow of the fluid was avoided, and allowed to stand for 10 minutes. The cover slip was then lifted upward, transferred on to the centre of a cleaned grease free glass slide and the formation of air bubbles was avoided. The already made wet film preparation was examined microscopically with $\mathrm{x} 10$ and $\times 40$ objective lenses for the presence of parasites' Cysts, Larvae and Ova or both. The results of reading were noted and recorded. 


\subsection{Data Analysis}

The data obtained were subjected to statistical tool of analysis by using total, mean and standard deviation in order to ascertain, verify the dispersions and the central tendency of the variables being obtained as described by Steel and Torrie, (1982), Stroud and Booth, (2001) and as performed by Umaru et. al, (2014).

\section{Results}

The results obtained from the faecal samples diagnosed by the different techniques, of the thirty (30) horses that were involved in the study are shown in the tables below as follow:

Table 1 showed the results of the mascroscopical examination carried out on the 30 faecal samples; the consistency of the faecal sample appearance has 30\% (9), presence of abnormal odour has $23 \%$ (7) abnormal colour has $17 \%$ (5), presence of blood had $23 \%$ (7), presence of mucus has $47 \%$ (14), Larvae seen had 7\% (2), undigested food particles seen has $17 \%$ (5) and presence of adult Helminthic parasites had $0 \%$. The mean number of trophozoites found by using $0.85 \%$ Normal Saline wet preparation were $8,1 \%$ solution of Lugol's Iodine were 10 and concentration technique using Saturated Salt Solution (SSS) were 5, the mean value was $8 \%$. Number of helminths ovae found by using Normal Saline wet preparation were $12,1 \%$ solution of Lugol's Iodine were 17, and concentration technique using Saturated Salt Solution (SSS) were 16, the mean value was $15 \%$. Number of helminths larvae found by using Normal
Saline wet preparation were 7, $1 \%$ solution of Lugol's Iodine were 6, and concentration technique using Saturated Salt Solution (SSS) were 10 , the mean value was $8 \%$. While adults helminthic parasites were not found in the all of the techniques used. The variables obtained shown to be significant at both vertical and horizontal levels.

Table 2 showed the results of the microscopical examination carried on the 30 faecal samples of the Horses by using Normal Saline $(0.85 \%$ of $\mathrm{NaCl}$ solution), wet preparation, and direct smear technique. The types of stages of parasites detected are; Protozoan cysts had 53\% (16), Protozoan trophozoites (vegetative forms) had 27\% (8), helminths ovae had $40 \%$ (12), helminths larvae had $23 \%$ (7), and adult helminths parasite had none $0 \%$.

Table 3 showed the results of the microscopical examination carried on the 30 faecal samples analysis of the Horses by using $1 \%$ solution of Lugol's Iodine, wet preparation direct smear technique. The types of stages of parasites found are; Protozoan Cysts had 60\% (18), vegetative forms of protozoa had 33\% (10), helminths ovae had 57\% (17), helminths larvae had $20 \%$ (6), and adult worm parasites had none $0 \%$.

Table 4 showed the results obtained from the microscopical examination carried on the 30 faecal samples analysis of the Horses by Concentration technique using Saturated Salt Solution ( Brine water), wet preparation direct smear technique. The types of stages of parasites detected are; Cysts of Protozoan had 70\% (21), trophozoites had17\% (5), helminths Ovae had 53\% (16), helminths larvae had 33\% (10), and then adult helminthic parasites had none $(0 \%)$.

Table 1. Macroscopic Examination of the Horses' Faecal Sample (Appearanc)

\begin{tabular}{llll}
\hline Types of Examination (Macroscopy). & Number of Samples Examined. & Number of Positive Cases. & Percentage of Positive Cases. \\
\hline Consistency. & 30 & 9 & 30.00 \\
Odour. & 30 & 7 & 23.33 \\
Colour. & 30 & 5 & 16.67 \\
Blood. & 30 & 7 & 23.33 \\
Mucus. & 30 & 14 & 46.66 \\
Larva. & 30 & 2 & 6.67 \\
Adult Parasite. & 30 & 0 & 0.00 \\
Undigested food Particles. & 30 & 5 & 16.67 \\
Mean \pm Standard deviation. & & $6 \pm 4$ & $21 \pm 14$ \\
\hline
\end{tabular}

Table 2. Microscopic Examination of the Horses' Faecal Samples Using Normal Saline Direct Smear.

\begin{tabular}{llll}
\hline Types of Examination (Microscopy). & Number of Samples Examined. & Number of Positive Cases. & Percentage of Positive Cases. \\
\hline Protozoan Cysts. & 30 & 16 & 53.33 \\
Protozoan Trophozoites. & 30 & 8 & 26.67 \\
Helminths Ovae. & 30 & 12 & 40.00 \\
Helminths Larvae. & 30 & 7 & 23.33 \\
Helminths Adult Parasite. & 30 & 0 & 0.0 \\
Mean \pm Standard deviation. & & $9 \pm 6$ & $29 \pm 20$ \\
\hline
\end{tabular}

Table 3. Microscopic Examination of the Horses' Faecal Sample using Lugols' Iodine Solution Direct Smear.

\begin{tabular}{llll}
\hline Types of Examination (Microscopy). & Number of Samples Examined. & Number of Positive Cases. & Percentage of Positive Cases. \\
\hline Protozoan Cysts. & 30 & 18 & 60.00 \\
Protozoan Trophozoites. & 30 & 10 & 33.33 \\
Helminths Ovae. & 30 & 17 & 56.67 \\
Helminths Larvae. & 30 & 6 & 20.00 \\
Helminths Adult Parasite. & 30 & 0 & 0.0 \\
Mean \pm Standard deviation. & & $10 \pm 8$ & $34 \pm 25$ \\
\hline
\end{tabular}


Table 4. Microscopic Examination of the Horses' Faecal Samples Using Saturated Salt Solution Concentration technique.

\begin{tabular}{llll}
\hline Types of Examination (Microscopy). & Number of Samples Examined. & Number of Positive Cases. & Percentage of Positive Cases. \\
\hline Protozoan Cysts. & 30 & 21 & 70.00 \\
Protozoan Trophozoites. & 30 & 5 & 16.67 \\
Helminths Ovae. & 30 & 16 & 53.33 \\
Helminths Larvae. & 30 & 10 & 33.33 \\
Helminths Adult Parasite. & 30 & 0 & 0.0 \\
Mean \pm Standard deviation. & & $10 \pm 8$ & $35 \pm 28$ \\
\hline
\end{tabular}

\section{Discussion}

The results obtained are based on the Comparative Parasitological Diagnostic Techniques been applied and 30 horses are involved in the study. The Macroscopical examination of the faecal samples on the abnormality of the consistency, odour and colour, the presence of blood, mucus, larvae, undigested food particles and adult helminthic parasites were observed. It revealed that the mean positivity is 6 with a mean percentage of $21 \%$ of incidence cases.

The microscopical examination of the faecal samples conducted by using the $0.85 \%$ Normal Saline solution Direct smear Wet Preparation technique, of which parasite such as protozoan cysts and their vegetative form, Helminths Ovae, larvae and adult form were searched. The results obtained revealed that, the mean positive cases were 9 and the percentage of prevalence is found to be $28 \%$.

In another finding, observations made on the microscopical examination of the faecal samples conducted by using the Lurgol's iodine solution direct smear wet preparations, in which different forms of the Gastrointestinal Parasites of Horses were searched for; the results of the finding revealed that the mean positivity was found to be 10 in number and the mean prevalence is $34 \%$.

The results obtained from the Concentration technique by floatation using the saturated salt solution (SSS) of sodium chloride ( $\mathrm{NaCl}$ Analar), the preparations were examined and thoroughly searched for the presence of parasites. It revealed that the mean positive cases are 10 and the mean percentage of prevalence is $35 \%$.

Also results obtained from this study, revealed that the total mean of Parasites found are 12 with percentage of prevalence of $20 \%$ approximately.

Summarily, the results obtained from the faecal samples of the Horses involved by using the 3 wet preparations techniques applied, are found to be as follows, total mean number of Protozoan cysts have $21(36 \%)$, vegetative forms have $10(17 \%)$, Helminths ova has $17(29 \%)$, larvae have 10 $(17 \%)$ and adult Parasites has $0(0 \%)$ respectively. The variables obtained from this research accepted.

\section{Conclusion and Recommendations}

\subsection{Conclusion}

Horses have been a valuable and prestigious social animal since some early years ago, which are used for various purposes by human. It became necessary to handle and give a proper management of the animal, including their health conditions. Frequent proper and accurate diagnoses of the animal wellbeing became necessary, especially, for the presence of Gastrointestinal Parasites where Parasitological diagnostic techniques have to be applied. For these reasons, it would have been better not to relay on a single technique of analysis, if an accurate results are needed, especially where the sample is scanty or in early Gastrointestinal Parasitic infection. When more diagnostic techniques are applied, there will be no the possibility of missing any Parasite if there is infection, it will reveals a higher results.

\subsection{Recommendations}

Based on the results obtained and in order to avoid frequent infection, we recommended that; when faecal samples are required to be analysing, Multiples Parasitological diagnostic techniques should be applied, and owners of Horses are urging to take their horse to a Veterinary Clinic or Hospital nearby for an accurate and appropriate diagnosis for the wellbeing of their animal routinely, after three month each (quarterly in a year), before given treatment.

\section{Acknowledgement}

It is a great pleasure to acknowledge with kind respects to the Laboratory Unit, A. H. P .T Department, Mohamet Lawan College of Agriculture, Maiduguri, Nigeria, for their contribution and assistance given to us. We owe particular thanks to all those researchers and their works cited in this piece of work, and also most grateful to all persons who haved helped or assisted in one way or the other in the course of carrying out this study successfully.

\section{References}

[1] Abbott, E.M, "Larval Cyathostomosis", In: Part 1 Equine Practice. 1998; 20, (3): 56-67.

[2] Budiansky, Stephen. "Microsoft ${ }^{\circledR}$ Encarta ${ }^{\circledR}$ [DVD]". Remond, WA: Microsoft Corporation, (C) 1997 - 2007, 2008.

[3] Crewe, W. "Haemoparasites". In: Blacklock and Southwell, A GUIDE TO HUMAN PARASITOLOGY, Laboratory Techniques, 10th edition, H.K. Lewis and Co Ltd, ELBS series; Pp. 177 - 186. 1977.

[4] Gwana, A.M; Auwal, M.S; Bagudu, B.Y. \& Gazali, Y.A. "Study Area and Location", In: Comparative of Parasitological Diagnostic Techniques in the Survey of Haemoparasites of Camel Slaughtered in Maiduguri Central Abattoir, North - eastern Nigeria, Journal of Laboratory Science, 2013; 1, (2): $57-65$. 
[5] Hall H.T.B, "African Horse Sickness", In: Diseases and Parasites of Livestock in the Tropics. Intermediate Tropical Agriculture Series. Longman Group Ltd, London, 1980; pp: $49-52$.

[6] Jorgensen, R. "Isolation of Infection. Dictyocaulus larvae from herbage", Vet. Parasitology. 1975; 16, (18) 16.

[7] Klei, T.R. "Parasites Control Programmes", In: Current Therapy in Equine Medicine 4, $1^{\text {st }}$ Ed, Robinson, E.N \& Saunders, W.B. Company. 1997; Pp. $71-74$.

[8] Knoss, K. H. "The Parasites of Livestock", World Animal Review; In: ILCA Monograph Series, 1977; 22: 29 - 35.

[9] Leaf Lang and Ileomobode. "Bovine Trypanosomes in Northern Nigeria., A contribution to the Epidemiology". Host sensitivity to T. vivax, In: A PhD Thesis. University of Utrecht, 9; 1977: pp. $11-19$.

[10] Lukens, A. G. "Protozoan diseases of Camels" Prac. $1^{\text {st }}$ Interim. Cont Camel. Dubai, UAE. 1992: 23 - 27.

[11] National Population Commission, "Census De Facto ", In: Census Report; Vital statistical Unit, Gidan Madara, Maiduguri, Borno State Nigeria. 2006.

[12] Oseyemi, T.I.O and Agboni Ahor. "Incidence of Protozoan Blood Parasites in Livestock in Northern Nigeria", Tropical Animal Health Production; 1980; $48-59$.

[13] Paris, J. "Livestock Diseases"; In: ACTA.Tropical, 1982: 39; 307.
[14] Paul, J.W. "Equine Larval Cyathostomosis", In: Parasitology, 1998; 20, (4): 7 -13.

[15] Peter; D.C, Gardon; J.B, Joseph; A.D, Walter; I, John; E.M, James; N.M, Michael; J.M, Sofie; M, Stanley; I.K, Susan; D.S \& Josie; L, Traub-Dargatz. "Common Gastrointestinal Parasites of Horses", In: Klei, T.R, Parasites Control Programmes, Current Therapy in Equine Medicine 4, Robinson, E.N \& Saunders, W.B. Company, $1^{\text {st }}$ Ed; 2011: Pp. $2-14$.

[16] Smyth, G.D. "Introduction to Animal Parasitology", Cambridge University Press, Cambridge, UK; 1996: Pp 266 268.

[17] Soulsby, E. J. L "Helminths, Arthropods and Protozoa of domesticated Animals", $1^{\text {st }}$ Ed; 1982: 34 - 42.

[18] Steel, R.G.D. and Torrie, J.K. "Analyses of Variance", Principles and Procedures of Statistics, Mc Grow Hill Book Company Inc, U.S.A, $2^{\text {nd }}$ Edition; 1980: 125 - 130.

[19] Stroud, K.A \& Booth, D.J. "Statistical Package", In: Engineering Mathematics.WWW. Palgrave.Com / Stroud, Pal grave, $5^{\text {th }}$ Edition, GB, London; 2001: $1130-1139$.

[20] Umaru; BW, A.B, Gwana; A.M, Wanas; L.N, Yachilla; BKM, Mohammed; U.K. Examinations of the Stomach Contents of Two Fish Species (Clarias gariepinus and Oreochromis niloticus) in Lake Alau, North - Eastern Nigeria. Agriculture, Forestry and Fisheries. 2014; 3, (5): pp.405 - 409.doi: 10.11648/j.aff.20140305.23. 